\title{
AMERICA'S OLDEST BASKETRY
}

\section{RAINER BERGER, MILLIE BENDAT and ANDREA PARKER}

Isotope and Archaeometry Laboratory, Institute of Geophysics and Planetary Physics University of California, Los Angeles, California 90095-1567 USA

\begin{abstract}
We have determined the earliest calibrated dates on three types of basketry from the Great Basin of western North America. The oldest twined basketry dates to 10,380-10,918 cal BP, reed duck decoys to 2355-2773 cal BP, and wooden sandals of sagebrush bark or twined tule to $9247-10,375$ cal BP and $9242-9836 \mathrm{cal} \mathrm{BP}$, respectively.
\end{abstract}

\section{INTRODUCTION}

In the Great Basin of western North America, preservation conditions are excellent for organic materials due to the aridity of the region. Over the years, several archaeological sites have yielded substantial amounts of various types of basketry. Often these sites are severely disturbed by rodents searching for food stored underground in the basketry. This makes direct dating paramount when establishing a chronological framework. We illustrate several basket-making techniques from this region with accompanying radiocarbon dates. The oldest twined basketry dates to $10,380-10,918$ cal BP. In addition to food handling containers, duck decoys made from reeds were also dated, documenting this ingenious mode of hunting as early as 2355-2773 cal BP. Finally, the Fort Rock and Cougar Mountain sandals (Oregon) made of woven sagebrush or twined tule, were dated to 9247 10,375 cal BP and 9242-9836 cal BP, respectively.

\section{DESCRIPTIVE BACKGROUND AND RESULTS}

\section{Basketry}

The Falcon Hill sites in Washoe County, Nevada, in the rain shadow of the Sierra Nevada, have yielded substantial amounts of basketry in an archaeological environment that is highly disturbed due to rodent activity (Hattori 1982). Many of these basketry fragments, presumably of food containers, were dated at UCLA (Berger, Fergusson and Libby 1965; Berger and Libby 1966) after standard decontamination.

From a stylistic point of view, these baskets were made by three techniques: coiling, plaiting and twining. The first case involves sewing a stationary, horizontal element (foundation or warp) with an active element (stitch or weft). Typical applications are containers, hats, trays and sometimes bags. In plaiting or unsewn weaving, perpendicular elements pass over and under each other. This technique was used for large baskets. Finally, in twining, there are paired active elements (weft) twisted on either side of stationary, vertical elements. Twining was most often used for containers. These styles are illustrated in Figures 1-5, with representative dates. It is interesting to note that based on only stylistic analysis, proper seriation would not have been possible, nor would it have been feasible to reconstruct the correct time sequence on the basis of stratigraphy alone. Thus ${ }^{14} \mathrm{C}$ dating became the only methodology to untangle the archaeological puzzle at Falcon Hill posed by its basketry components.

All conventional ${ }^{14} \mathrm{C}$ dates in this paper were originally calibrated after Stuiver and Reimer (1993). After the 1997 Groningen ${ }^{14} \mathrm{C}$ Conference, it was pointed out that as yet no internationally accepted calibration curve exists for the period before $c a .5000 \mathrm{cal} \mathrm{BC}$. In fact, at this conference, M. Spurk and B. Kromer announced several corrections for the existing Southern German Oak Chronology and a new correlation of the floating pine chronology and the corrected oak chronology (Spurk et al. in press). Thus the present calibrated date for the oldest basketry is actually too young by several hun- 
dred years, so a revision will be necessary after a modernized calibration has been calculated and published. (The same argument applies to the dates of the sandals below.)

Fig. 1. Coiled technique, Wa200/UCLA-674. Earliest date for coiled technique $2440 \pm$ $100 \mathrm{BP} / 2345-2722$ cal BP.
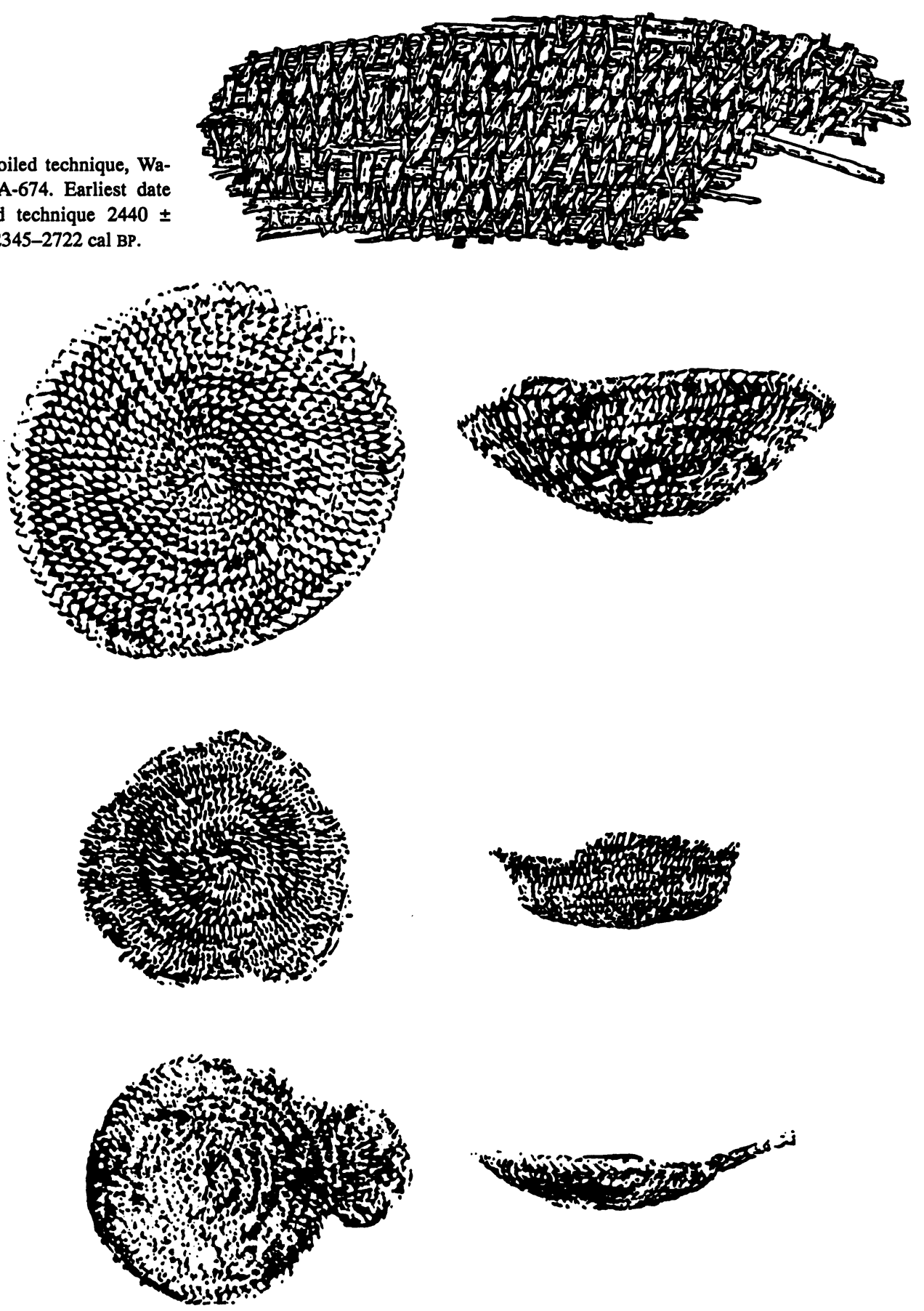

Fig. 2. Coiled technique used in a basket, Wa-205/UCLA-668. Date: $1150 \pm 100 \mathrm{BP} / 945-1171 \mathrm{cal} \mathrm{BP}$. 

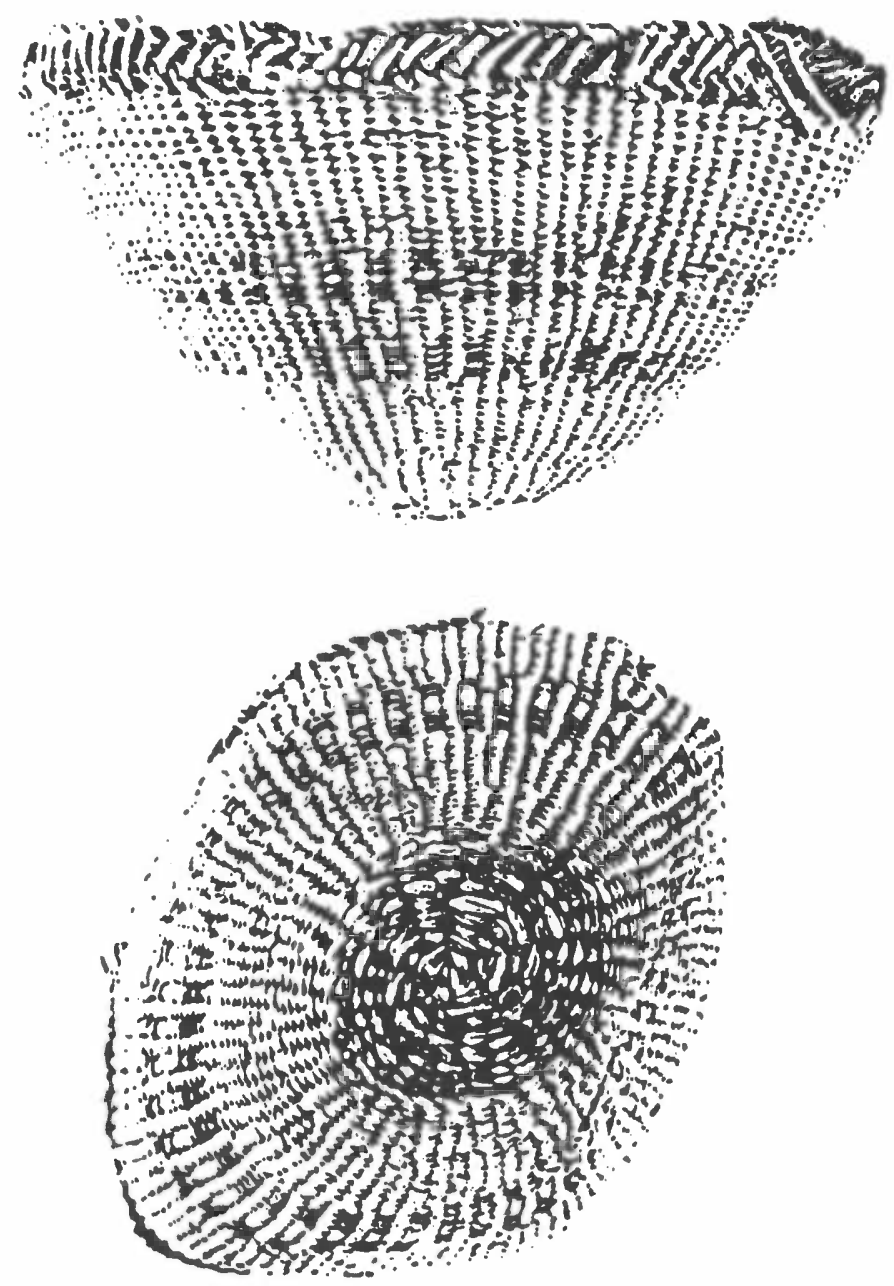

Fig. 3. Plain two-element S-twining. Wa196/UCLA-670. Last known occurrence $3900 \pm 100 \mathrm{BP} / 4150-4438 \mathrm{cal}$ BP.

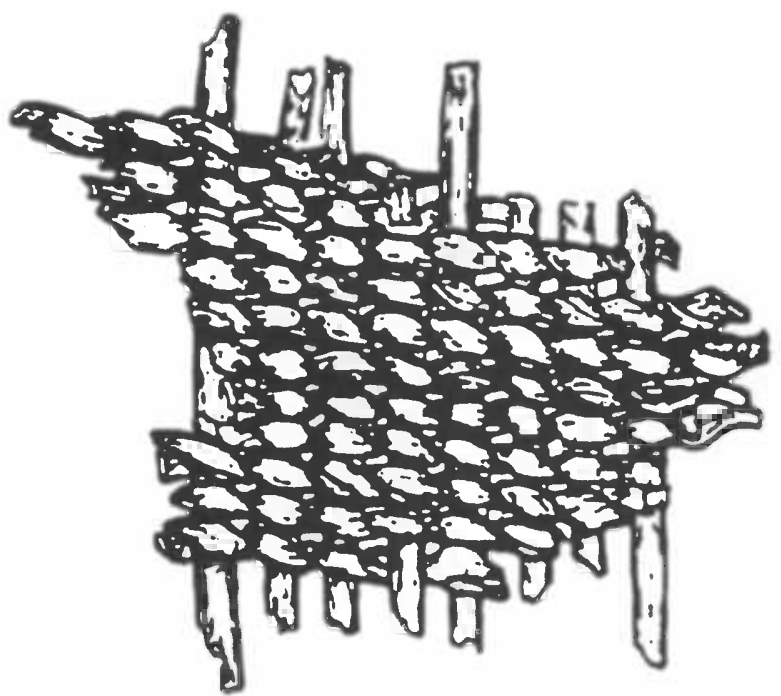

Fig. 4. Twined basketry. Wa-198/UCLA-675. Oldest known basketry in America: $9540 \pm 120$ BP / 10,380-10,918 cal BP. 
Fig. 5. Plaited basketry, Wa-200/ UCLA-677. Example of plaited technique known as Lovelock wickerware. Latest known occurrence: $580 \pm 100 \mathrm{BP} / 520-670 \mathrm{cal}$ BP.
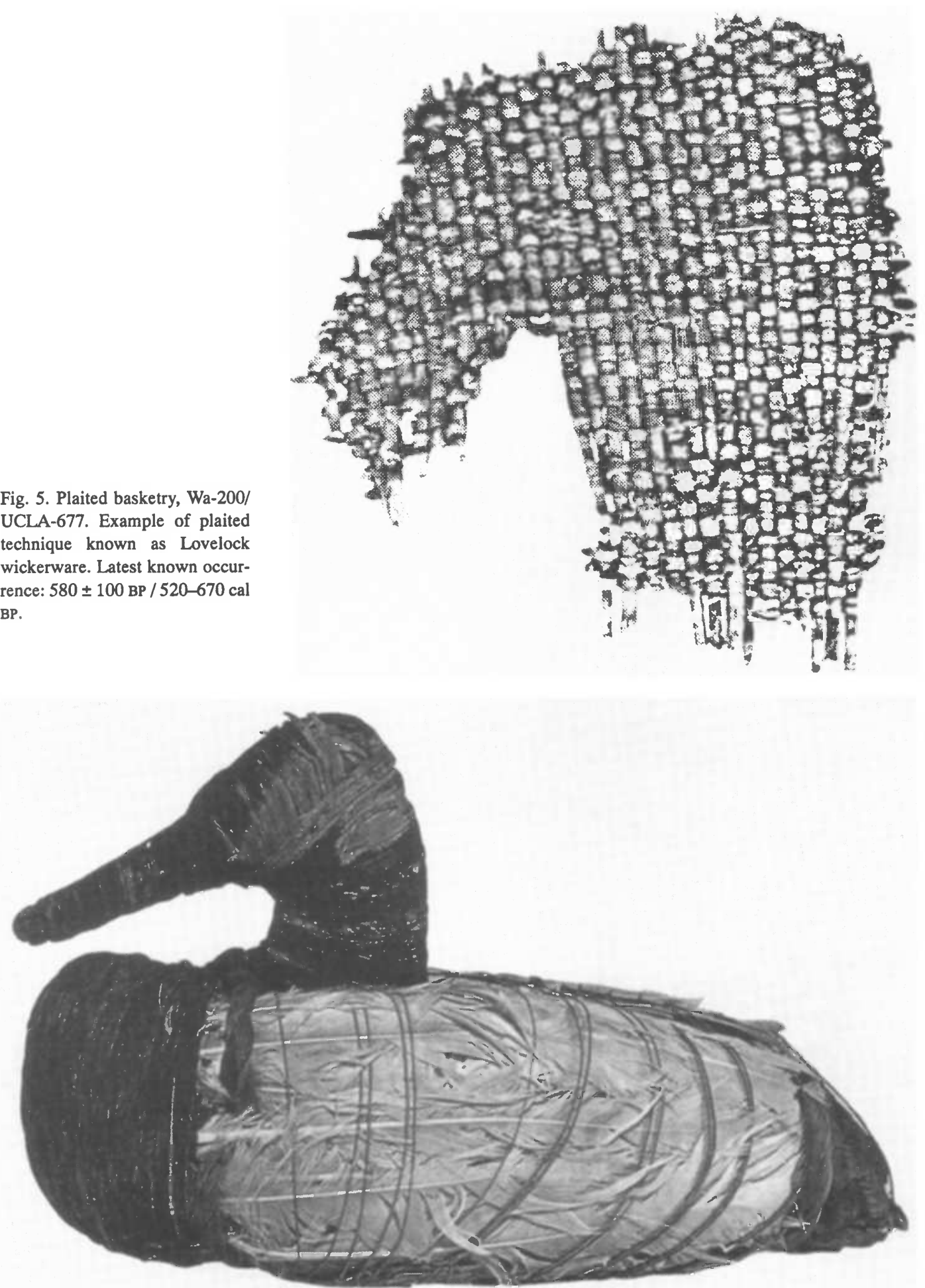

Fig. 6. Reconstruction of a duck decoy 


\section{Duck Decoys}

These were made out of materials similar to those of the basketry. They were adorned more fully to resemble ducks during hunting. The specimens dated here originate in Lovelock Cave, Nevada, just east of the Falcon Hill sites, and from an unknown location, collected during the same expedition by M. Harrington and L. L. Loud in $1924 .{ }^{1}$ A reconstruction of a duck decoy is illustrated in Figure 6. The specimen from Lovelock Cave dates from $2540 \pm 150 \mathrm{BP}(2355-2773 \mathrm{cal} \mathrm{BP})$, while the other is from $1290 \pm 165$ BP (992-1327 cal BP). One may speculate that even older decoys may be found in the future since the methodology to produce them had been available for thousands of years.
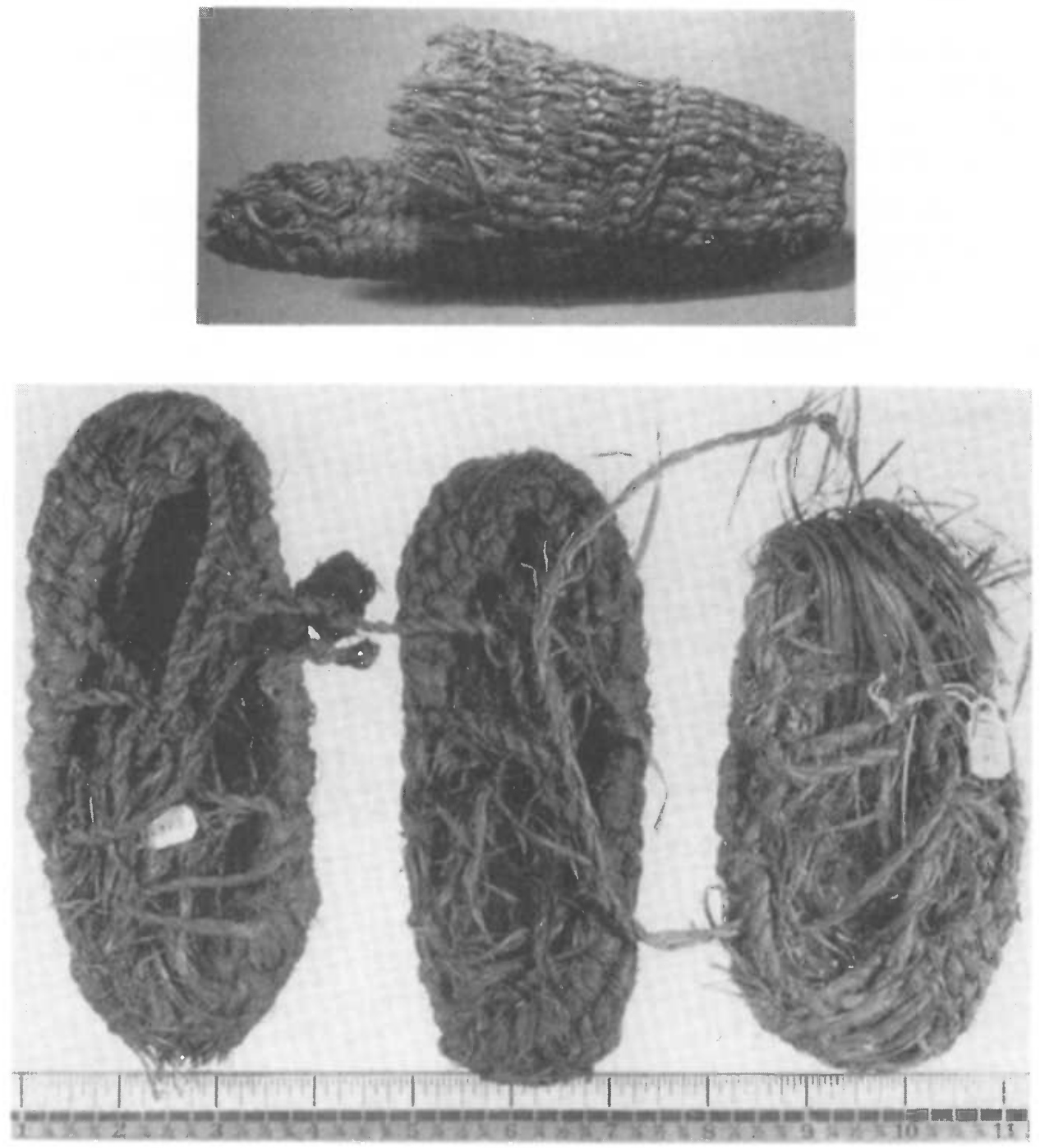

Fig. 7. Fort Rock, Oregon sandals

\footnotetext{
${ }^{1}$ Samples were obtained from the Heye Foundation, New York. The Lovelock specimen is identified as 13/4512-B from pit 12 ; the other specimen is $13 / 4517$.
} 


\section{Sandals}

The Fort Rock sandals (Fig. 7) are the same ones dated by Libby (1955). They are made of shredded sagebrush, with bark shreds twisted counterclockwise into rope that in turn runs around the length of the sole into a series of warps and subsequently into wefts woven above and below the warps. The sole is made too long initially, then folded back and mated to the sole on the edges to form the top of the slipper. A decorative braid runs over the arch of the foot. Libby's Chicago laboratory calculated a date of $9053 \pm 350 \mathrm{BP}$, which is equivalent to $9247-10,375 \mathrm{cal}$ BP. A similar type of sandal was also found at Cougar Mountain Cave, Oregon, and dated to $8410 \pm 250 \mathrm{BP}$ or $9242-9836 \mathrm{cal} \mathrm{BP}$.

\section{ConCLUSION}

Inspection of the basketry and sandal dates shows that the American native population was well capable of manufacturing needed human accessories over $10 \mathrm{ka}$ ago. It remains a question whether the basketry techniques were also used on a more macroscopic scale to build shelters, inasmuch as the twining technique resembles interior construction of wattle-and-daub.

Insofar as different basket-weaving techniques can be correlated to various American Indian cultures, absolute dates for the earliest-known samples of diagnostic basketry in America should be of interest to New World linguists as they reconstruct the evolution and dispersal of American Indian languages. Moreover, Old World linguists who investigate the antecedents of American Indian languages in the Old World may wish to use these absolute dates in their glottochronological frameworks.

\section{ACKNOWLEDGMENT}

This is publication number 5084 of the Institute of Geophysics and Planetary Physics, UCLA.

\section{REFERENCES}

Berger, R., Fergusson, G. J. and Libby, W. F. 1965 UCLA radiocarbon dates IV. Radiocarbon 7: 336-371.

Berger, R. and Libby, W. F. 1966 UCLA radiocarbon dates V. Radiocarbon 8: 467-497.

Hattori, E. M. 1982 The archaeology of Falcon Hill, Winnemucca Lake in Washoe County, Nevada. Nevada State Museum. Anthropological Pap.-No. 18: 208 p.

Libby, W. F. 1955 Radiocarbon Dating. 2nd ed. Chicago, University of Chicago Press: $175 \mathrm{p}$.

Spurk, M., Hofmann, J., Friedrich, M., Sabine, R.,
Leuschner, H. H. and Kromer, B., in press, Revision and extension of the German oak and pine chronologies: New evidence about the timing of the Younger Dryas/Preboreal transition. In Stuiver, M., ed., Calibration 1998. Radiocarbon, in press.

Stuiver, M. and Reimer, P. J. 1993 Extended ${ }^{14} \mathrm{C}$ data base and revised CALIB $3.0{ }^{14} \mathrm{C}$ age calibration program. In Stuiver, M., Long, A. and Kra, R. S., eds., Calibration 1993. Radiocarbon 35(1): 215-230. 